\title{
Mechanical strength and microstructure evolution of fly ash cement mortar submerged in pig slurry
}

\author{
E. Sánchez , J. Massana , M.A. Garcimartín , A. Moragues \\ Polytechnic University of Madrid, Department of Applied Science and Technology, Ciudad Universitaria s/n, 28040 Madrid, Spain \\ Polytechnic University of Madrid, Department of Construction and Rural Roads, Spain \\ Polytechnic University of Madrid, Department Civil Engineering: Construction, Spain
}

\begin{abstract}
This paper studies the behaviour of mechanical strength and porosity of mortars made with three types of cement with different fly ash content. The trials were carried out under real conditions with natural pig slurry. The three mortars were submerged at depths of 1 and $3 \mathrm{~m}$ in slurry in an experimental lagoon. Control samples were situated in the open air in the natural environment. The total duration of the experiment was 24 months. The variation in the flexural and compressive strength in the specimens was checked at 3,12 and 24 months by carrying out standardised tests. An increase in flexural and compressive strength in all cements was noted in the two submerged environments, which is explained as a result of a decrease of pore size produced in the external part of specimens.
\end{abstract}

Keywords: Mortar; Fly ash; Flexural and compressive strength; Pig slurry; Mercury porosimetry

\section{Introduction}

The application of animal manure, such as pig slurry, is a common practice in both intensive and extensive agrarian farms

. However, such practices can cause contamination in surface or subterranean water channels. Good practice goes hand in hand with the agricultural cycle, which generally necessitates the storage of reasonably large quantities of these waste products, be it in lagoons or tanks . These must be capable of holding several months' worth of slurry. Accidental leakage from these storage sites can lead to significant contamination of ground or water. In the rural environment, reinforced concrete is the main construction material used. The objectives of this study are to investigate the resistance behaviour, change in porosity and mineralogical alteration of the cements tested whilst in contact with slurry.

Slurry has a variable and chemically complex composition which depends on factors such as the physiology of the animal, the type of feed, the typology and management of the facility, etc. It contains mineral and organic compounds from three main groups: acetic and propionic organic acids, nitrogenous compounds, (mainly ammoniac types) and different hydrous sulphate salts from the urea. The result is an aggressive agent with an average $\mathrm{pH}$ of 7 . Due to this value and according to established knowledge in the Spanish Standard of Structural Concrete, slurry should be considered a non-aggressive substance However, research data shows that in agrarian facilities in contact with slurry, both mortars and concretes deteriorate systematically to the point of producing serious losses in mechanical strength . This proves that the process of degradation is determined by the synergy of the different factors present. Various investigators are trying to reproduce these processes of concrete degradation under laboratory conditions

. They are testing different cements that have been exposed to isolated organic acids with different $\mathrm{pH}$ values or analyzing the cement matrix alteration mechanisms produced by the mixing of these acids

In this paper the results of mechanical strength tests are shown for three different cement mortars with differing fly ash 
Table 1

Chemical and mineral composition of cements used

\begin{tabular}{|c|c|c|c|c|c|c|c|c|c|}
\hline & $\mathrm{CaO}$ & $\mathrm{SiO}_{2}$ & $\mathrm{Al}_{2} \mathrm{O}_{3}$ & $\mathrm{Fe}_{2} \mathrm{O}_{3}$ & $\mathrm{MgO}$ & $\mathrm{K}_{2} \mathrm{O}$ & $\mathrm{SO}_{3}$ & $\mathrm{Cl}$ & $\begin{array}{l}\text { Ignition } \\
\text { loss }\end{array}$ \\
\hline $\begin{array}{c}\text { CEM } \Pi / \mathrm{B}-\mathrm{V} \\
32.5 \mathrm{~N}\end{array}$ & 35.19 & 47.86 & 7.38 & 3.3 & 1.26 & 1.18 & 1.64 & 0.007 & 2.21 \\
\hline $\begin{array}{c}\text { CEM II/A-V } \\
42.5 \mathrm{R}\end{array}$ & 48.21 & 35.35 & 5.67 & 3.6 & 1.74 & 1.35 & 2.23 & 0.008 & 1.78 \\
\hline $\begin{array}{c}\mathrm{CEM} \text { IV/B(V) } \\
32.5 \mathrm{~N}\end{array}$ & 26.05 & 57.45 & 7.4 & 3.5 & 1.24 & 1.39 & 1.26 & 0.006 & 1.69 \\
\hline
\end{tabular}

content. They were exposed to pig slurry from a pig farm for a period of 24 months. The same mortars were also exposed to the natural environment. The evolution of mechanical strength behaviour has been studied by means of flexural and compressive tests at 3,12 and 24 months. In addition, the change in the porosity and mineralogical characteristics are shown.

\section{Materials and methods}

\subsection{Cements}

This study was carried out on cement mortars made with three types of cement, each with different fly ash content: CEM II/ A-V 42.5 R, CEM II/ B-V 32.5 N and CEM IV/B (V) $32.5 \mathrm{~N}$.
The chemical and mineral compositions of the cements are shown in Table 1. The cements used came from private factories; therefore the exact fly ash content is confidential. However the possible ranges of fly ash content are specified in UNE-EN 197-1:2000. These are: 6-20\% for CEM II/ A-V 42.5 R, $21-35 \%$ for CEM II/ B-V $32.5 \mathrm{~N}$ and $36-55 \%$ for CEM IV/ $\mathrm{B}$ (V) $32.5 \mathrm{~N}$.

36 specimens of $40 \times 40 \times 160 \mathrm{~mm}$ were made for each cement type, as per regulation EN 196-1:1994, with a water to cement ratio of 0.5 and sand to cement ratio of 3 . The specimens were removed from the moulds after 24 hours and cured in water for 28 days at $22^{\circ} \mathrm{C}$. Subsequently they were kept for $48 \mathrm{~h}$ at $22 \pm 2{ }^{\circ} \mathrm{C}$ and $50 \%$ relative humidity. They were then immersed in the aggressive medium.

\subsection{Aggressive medium}

The aggressive medium used was pig slurry. This slurry came from the storage lagoon of a pig farm situated in Etreros, (Segovia). The climatic conditions in the area are $48 \%$ relative humidity and an average temperature of $20^{\circ} \mathrm{C}$ in summer and $75 \%$ and $9^{\circ} \mathrm{C}$ for the rest of the year. There is frost for 56 days a year. The slurry used was collected from the storage lagoon and transferred to an experimental lagoon. This was situated in the open air close to the storage lagoon. The experimental lagoon was constructed with two separate environments: one aerobic or
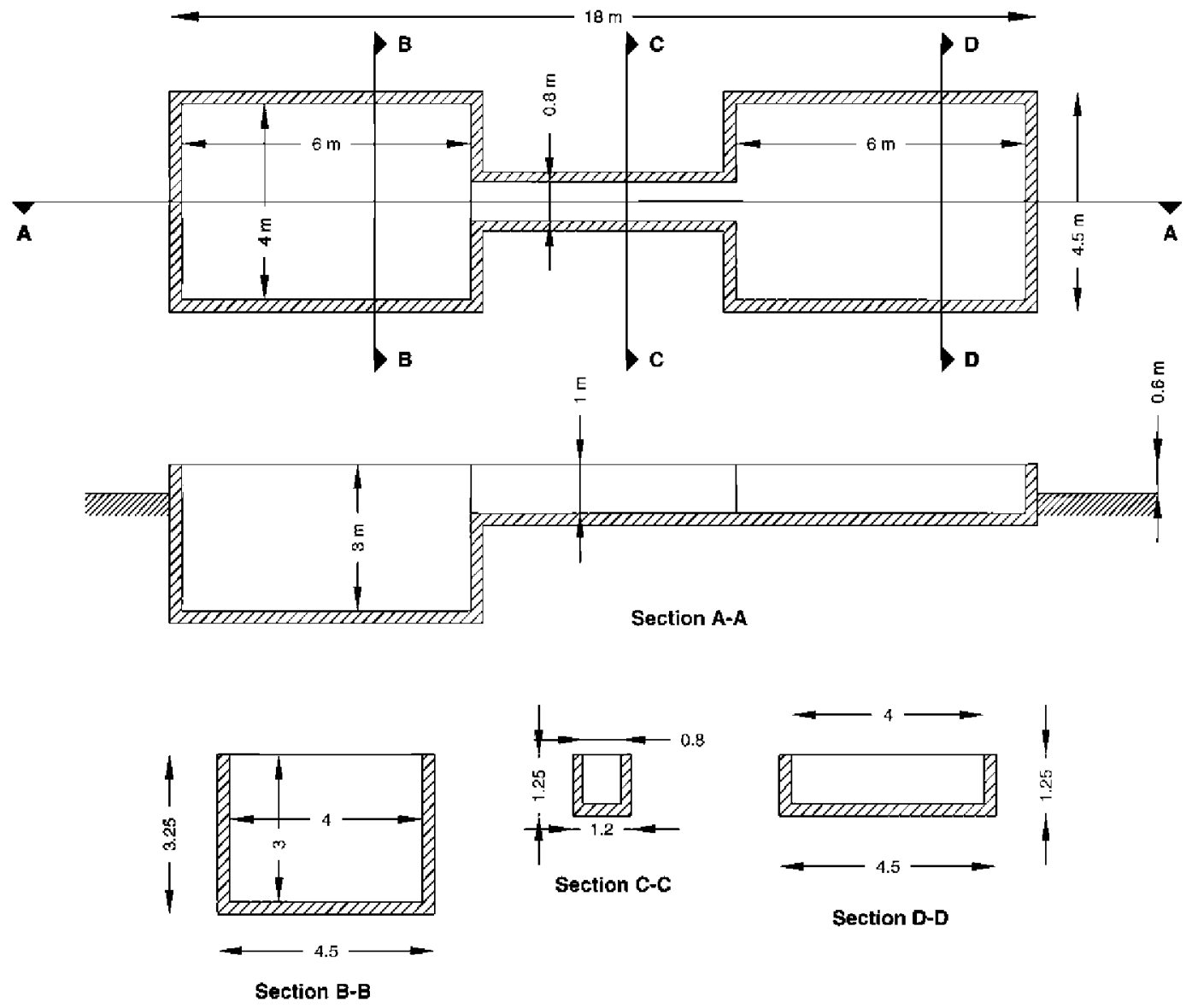

Fig. 1. Design and dimensions of the experimental lagoon. 
Minimum, maximum and average values of the slurry composition

\begin{tabular}{|c|c|c|c|c|c|c|c|}
\hline & & \multicolumn{3}{|c|}{ Aerobic environment } & \multicolumn{3}{|c|}{ Anaerobic environment } \\
\hline & & Minimum & Average & Maximum & Minimum & Average & Maximum \\
\hline \multicolumn{2}{|l|}{$\mathrm{pH}$} & 7.43 & 7.94 & 8.20 & 7.39 & 7.84 & 8.13 \\
\hline \multicolumn{2}{|c|}{ Conductivity (mS) } & 5.68 & 8.92 & 13.25 & 5.62 & 8.89 & 13.95 \\
\hline \multicolumn{2}{|c|}{ Redox potential $(\mathrm{mV})$} & -304.00 & -169.38 & -71.00 & -345.00 & -199.13 & -62.00 \\
\hline \multicolumn{2}{|c|}{ Total solids (mg/l) } & 4.07 & 5.87 & 7.19 & 4.34 & 25.34 & 80.81 \\
\hline \multicolumn{2}{|c|}{ Volatile solids $(\mathrm{mg} / \mathrm{l})$} & 2.04 & 2.95 & 3.98 & 2.38 & 17.37 & 59.54 \\
\hline \multicolumn{2}{|c|}{ Total nitrogen $(\%)$} & 0.06 & 0.12 & 0.20 & 0.06 & 0.20 & 0.31 \\
\hline \multicolumn{2}{|c|}{ Ammoniac nitrogen $(\%)$} & 0.05 & 0.09 & 0.12 & 0.05 & 0.13 & 0.23 \\
\hline \multicolumn{2}{|c|}{ Sulphurs (mg/l) } & 5.36 & 71.32 & 105.00 & 4.80 & 91.42 & 162.87 \\
\hline \multicolumn{2}{|c|}{ Bicarbonates (mg/l) } & 3.38 & 5.68 & 10.55 & 3.37 & 7.03 & 11.60 \\
\hline \multirow[t]{2}{*}{ Anions } & Sulphurs (mg/l) & 0.00 & 4.51 & 9.70 & 0.00 & 32.77 & 177.95 \\
\hline & Chlorides $(\mathrm{mg} / \mathrm{l})$ & 61.00 & 453.04 & 1388.00 & 209.00 & 416.37 & 628.00 \\
\hline \multirow[t]{3}{*}{ Acids } & Acetic $(\mathrm{mg} / \mathrm{l})$ & 32.55 & 153.79 & 286.70 & 7.86 & 67.03 & 145.00 \\
\hline & Propionic (mg/l) & 0.00 & 40.96 & 124.60 & 0.00 & 16.60 & 76.80 \\
\hline & Isovaleric $(\mathrm{mg} / \mathrm{l})$ & 0.00 & 2.15 & 3.50 & 0.00 & 0.39 & 1.20 \\
\hline
\end{tabular}

not very anaerobic, with a maximum depth of $1 \mathrm{~m}$ and another anaerobic section $3 \mathrm{~m}$ deep. The two parts of the lagoon were connected by a canal to facilitate the filling process (Fig. 1). The slurry was replaced at 3, 6, 12, and 18 months. Before replacement the composition of each part was analysed. The minimum, maximum and average values of each section are shown in Table 2. The main components of the compounds that make up the slurry are ammoniac nitrogen, sulphurs, chlorides, acetic and propionic acids. The amount of ammoniac nitrogen $\left(\mathrm{NH}_{4}^{+}\right)$alone, before taking into account the other compounds, is sufficient for slurry to be classified as a substance of medium to high aggressivity, under the Spanish Standard of Structural Concrete guidelines. Also the chloride content, caused by the water used to clean the livestock farm, gives the slurry a salinity close to that of sea water. The $\mathrm{pH}$ values are significant, as values between 7.5 and 8 mean slurry is an aggressive compound in relation to the cement which has a $\mathrm{pH}$ of 12 .

\subsection{Experimental procedures}

The specimens were submerged in each part of the lagoon at depths of 1 and $3 \mathrm{~m}$ respectively. Samples were also placed outside the lagoon, between the two sections, near to the connecting canal. In this way the samples were considered to have

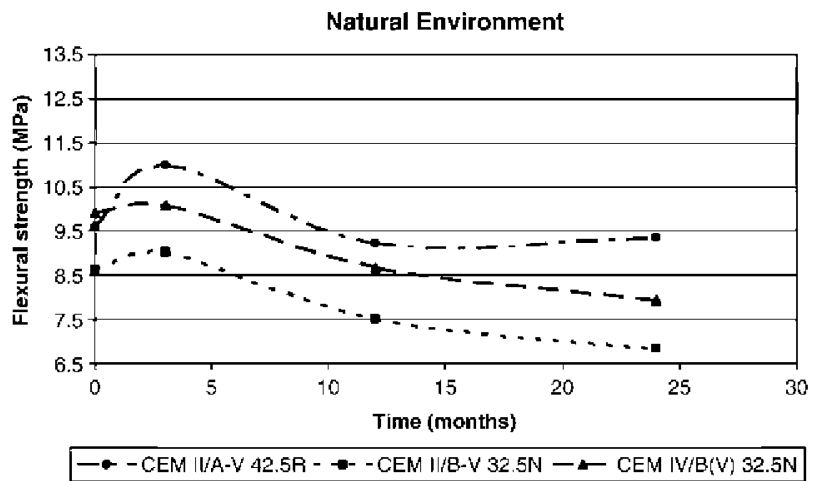

Fig. 2. Variation of flexural strength in the natural environment. been exposed to 3 types of environment: I) a natural environment with full availability of oxygen and carbon dioxide; II) submerged in slurry at a depth of $1 \mathrm{~m}$, with low to medium oxygen content and in the presence of aerobic fermentation reactions, and III) submerged in slurry at a depth of $3 \mathrm{~m}$ without oxygen and with the presence of anaerobic fermentation reactions.

After 3, 12 and 24 months three specimens of each cement type were removed from each environment. The specimens were cleaned with water and then immersed in water for $48 \mathrm{~h}$. After that the mechanical tests were carried out. The flexural and compressive measurements were carried out in a universal test machine according to the current Spanish Standard EN 196$1: 1994$.

The microstructure characterisation was carried out after 24 months of attack from the aggressive medium. The mercury intrusion porosity trials were carried out in a Termo Quest 2000. The samples, weighing approximately $3 \mathrm{~g}$ each, were obtained from the outside face and the centre of the specimen. They were tested upon reaching a constant weight, with an accuracy of $0.01 \mathrm{~g}$. The weight stabilisation process was carried out in an oven at $40{ }^{\circ} \mathrm{C}$.

The X-ray analysis was carried out by the Technical Service of the Material Science Institute of the Higher Council for

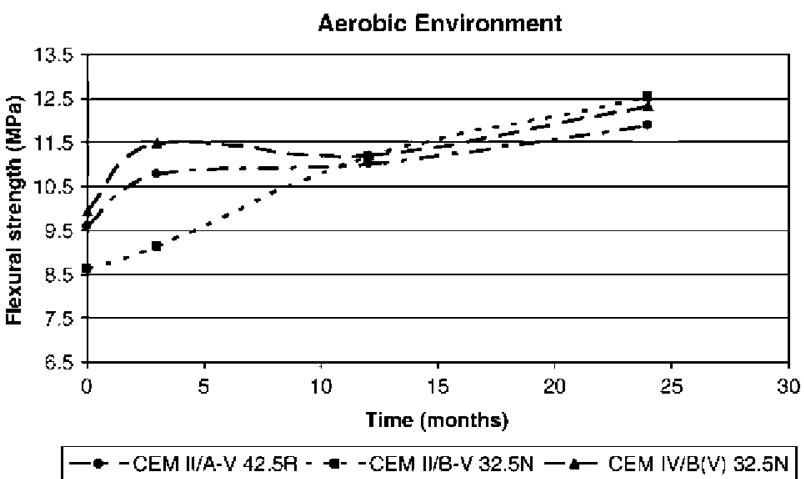

Fig. 3. Variation of flexural strength in the aerobic environment. 


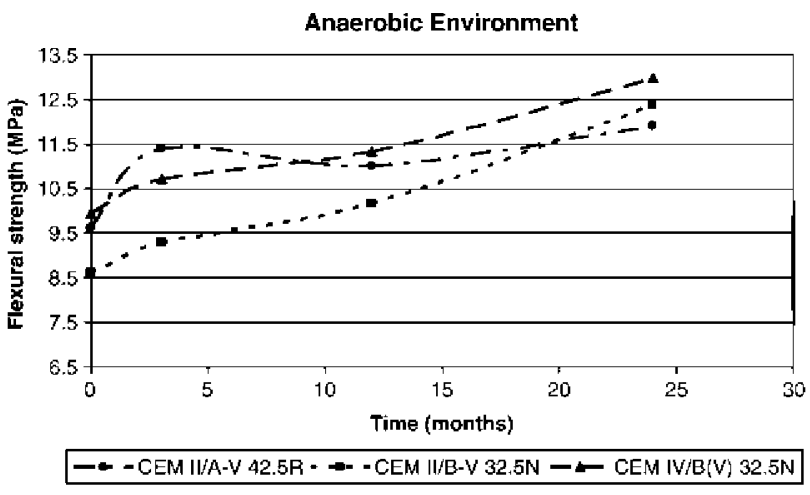

Fig. 4. Variation of flexural strength in the anaerobic environment.

Scientific Investigation (Spain), with a one minute exposure time to a cathode of $\mathrm{Cu} \mathrm{K} \alpha$. The sample was prepared by drying it at $40^{\circ} \mathrm{C}$ and then crushing it with partial elimination of some aggregates.

\section{Results and discussion}

\subsection{Flexural strength}

In all the cements exposed to the natural environment, (Fig. 2), there was an increase in strength in the first three months and then a loss in strength of $15 \%$ to $20 \%$ up to the 12 month point. The CEM II/B-V and CEM IV/B(V) cements showed a reduction in flexural strength from 12 to 24 months. In practical terms the CEM II/A-V cement maintained its strength. The authors think that the increase in strength of the three cements studied is due to the increase in the level of hydration. Different authors show similar results in the relationship between the progression of hydration age and the increase in strength for cement mortar with fly ash. . The strength of type 42.5 resistant cement is greater that of type 32.5 resistant. The test began in July, so the 3 to 9 month stage of the test included a period of low temperatures. At this time of year heavy frosts are common in the area of the farm, which explains the variances in resistance observed.

In the aerobic environment, (Fig. 3) there was an increase in flexural strength, which was sustained until the 24 month. The

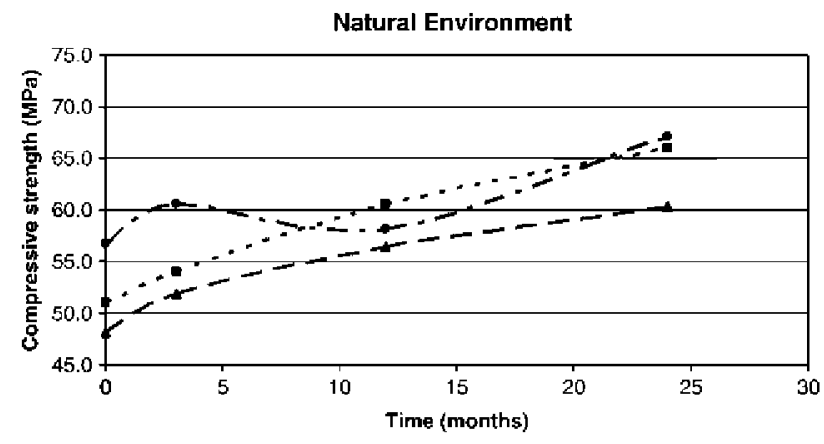

-* - CEM IVA-V 42.5R - - - CEM IIJB-V 32.5N - - CEM IVHB(V) 32.5N

Fig. 5. Variation of compressive strength in the natural environment.

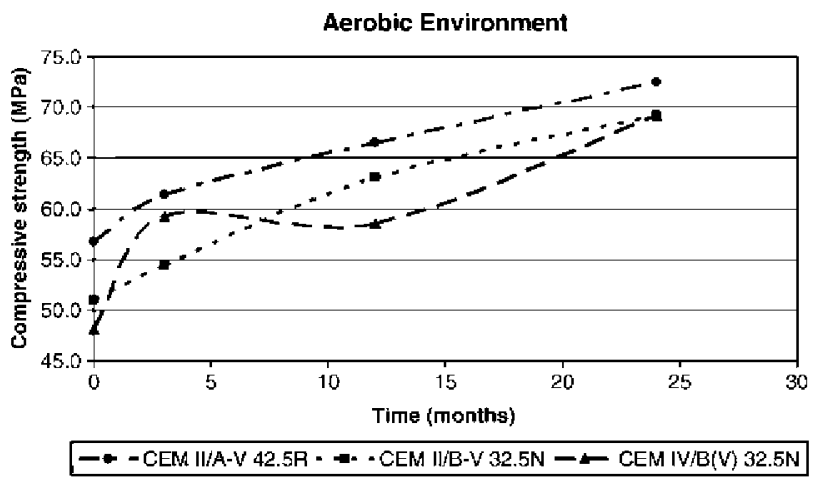

Fig. 6. Variation of compressive strength in the aerobic environment.

CEM II/A-V and CEM IV/B(V) showed similar behaviour. The increase in strength in the CEM II/B-V cement is similar to the previously mentioned cements from 12 months of exposure onwards. At 24 months the CEM II/A-V cement shows the smallest variation in strength. The increase in strength of CEM II/B-V is significantly higher than the other cements. The flexural strength behaviour in the anaerobic environment (Fig. 4) is similar to that of the aerobic environment. Variations in strength are insignificant from 12 months onwards.

\subsection{Compressive strength}

In the natural environment all the cements showed increases in compressive strength through time (Fig. 5). At the three month point, flexural and compressive strength show the greatest increases for all three cement types. At 24 months CEM II/B-V and CEM II/A-V show equal levels of compressive strength.

In the aerobic and anaerobic environments, (Figs. 6 and 7), all the cement types show sustained increases in compressive strength. The increase is equal in both environments. However, the increase in strength is greater in the submerged samples than those exposed to the natural environment. The increase is $28 \%$ for CEM II/A-V, 36\% for CEM II/B-V and $41 \%$ for CEM IV/B (V). Under compression the micro-cracks caused by the freezethaw cycle have no mechanical effect.

The increase in strength observed in the submerged environments (aqueous solvents) can be explained by an

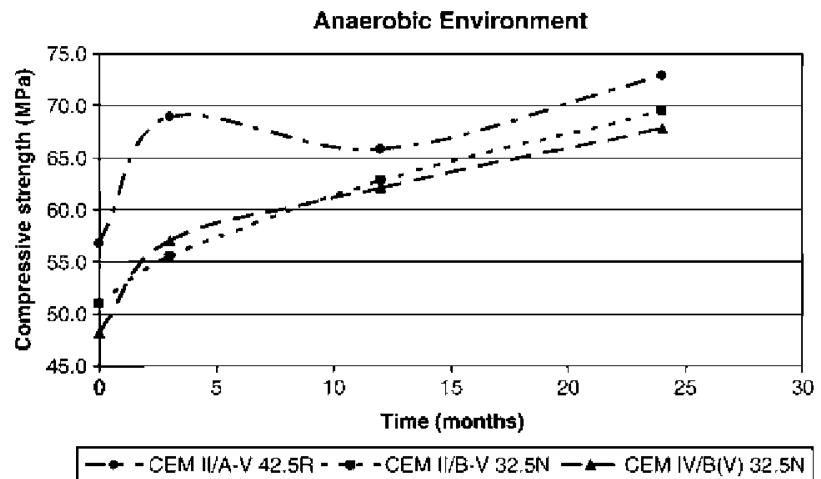

Fig. 7. Variation of compressive strength in the anaerobic environment. 
Table 3

Total porosity values by mercury intrusion porosimetry expressed in volume percentage

\begin{tabular}{|c|c|c|c|c|c|c|}
\hline & \multicolumn{2}{|c|}{$\begin{array}{l}\text { Outside } \\
\text { environment }\end{array}$} & \multicolumn{2}{|c|}{$\begin{array}{l}\text { Aerobic } \\
\text { environment }\end{array}$} & \multicolumn{2}{|c|}{$\begin{array}{l}\text { Anaerobic } \\
\text { environment }\end{array}$} \\
\hline & External & Internal & External & Internal & External & Internal \\
\hline CEMIL/B-V $32.5 \mathrm{~N}$ & 9.14 & 11.7 & 11.05 & 12.3 & 10.74 & 12.5 \\
\hline $\begin{array}{l}\mathrm{CEM} \text { IV/B(V) } \\
32.5 \mathrm{~N}\end{array}$ & 8.96 & 10.9 & 10.14 & 12.23 & 10.71 & 11.14 \\
\hline CEM II/A-V $42.5 \mathrm{~N}$ & 8.54 & 9.13 & 9.32 & 9.26 & 9.47 & 9.25 \\
\hline
\end{tabular}

increase in the level of hydration, according to various authors

\subsection{Porosity tests}

The porosity results are shown in Table 3 . For each of the environments studied porosity was measured in the centre of the sample and in the outside face. A clear trend exists of reduced porosity in the external part of the sample. The CEM II/A-V 42.5, with less fly ash content, has a lower porosity level than those of strength class 32.5, which concurs with results of Yong-Xin Li et al. This could cause a reduction in the capillary network which would restrict the diffusion of this medium in the internal part of the sample, thus accounting for the fact that the increases in strength are smaller in this cement type. The mechanical behaviour in the long term is similar to the lower strength class. This cement also shows the least percentage change between porosity in the internal and external parts of the sample. Even in submerged environments there are no variations.

The internal parts of the mortar samples taken from the natural environment have lower levels of porosity than those taken from the submerged environments.

Fig. 8 shows the distribution of pore sizes for the internal and external parts of the CEM II/B-V cement in the aerobic environment. Fig. 9 shows the distribution of pore sizes for the

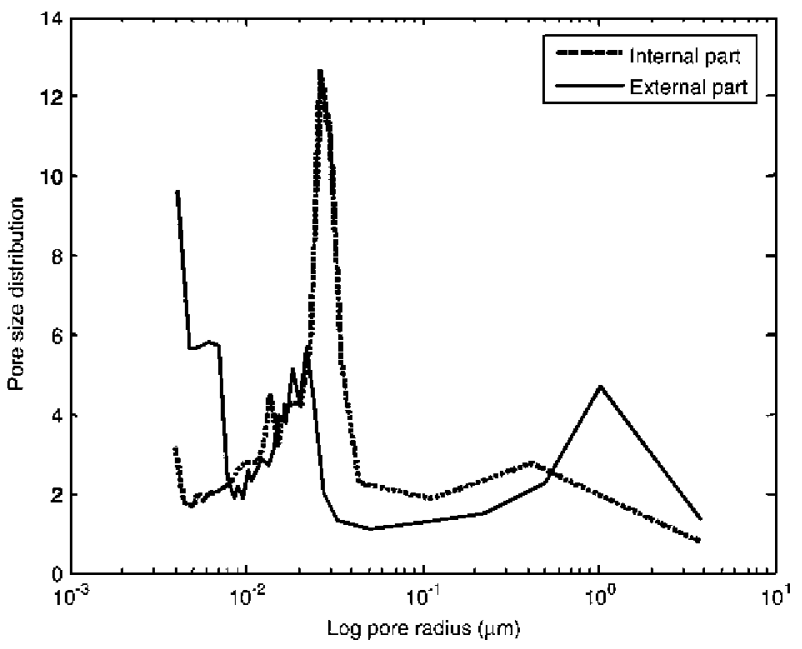

Fig. 8. Pore-size distribution for the CEM II/B-V $32.5 \mathrm{~N}$ cement in the aerobic environment.

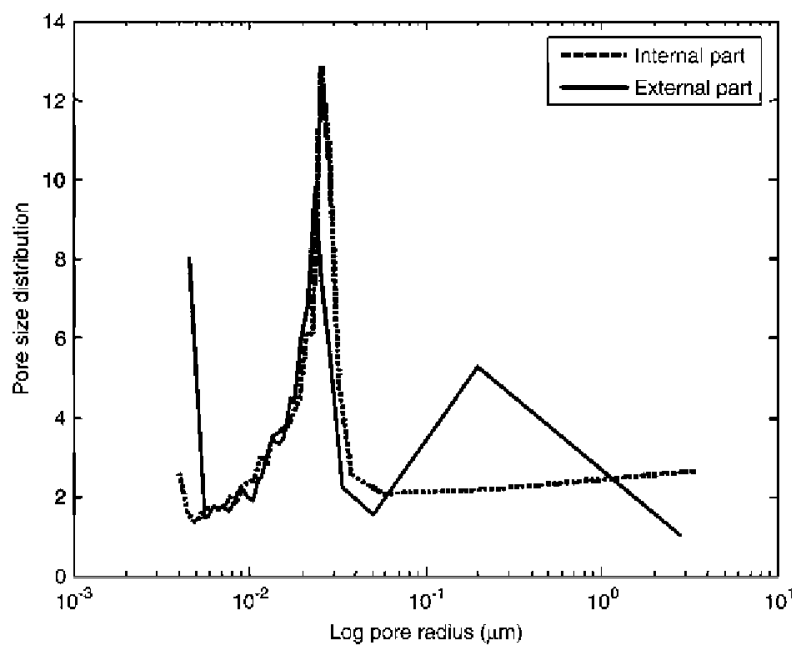

Fig. 9. Pore-size distribution for the CEM IV/B(V) $32.5 \mathrm{~N}$ cement in the anaerobic environment.

internal and external parts of the CEM IV/B(V) cement in the anaerobic environment and Fig. 10 shows the same distribution in CEM II/A-V cement in the natural environment. In the cements of strength class 32.5 the pore distribution shows a reduction in quantity of the largest size pores between the outside face and the centre. Figs. 8 and 9 show an increase in the size of the smallest pores and a significant reduction of pores between $10^{-2}$ and $10^{-1} \mu \mathrm{m}$, leading to an overall reduction in average pore size. In CEM II/A-V cement the pore distribution between the external part and the internal part appears practically unaltered, as with the total porosity.

\subsection{X-ray analysis}

Three cement samples were analysed. The samples were prepared by taking material from specimens submerged in

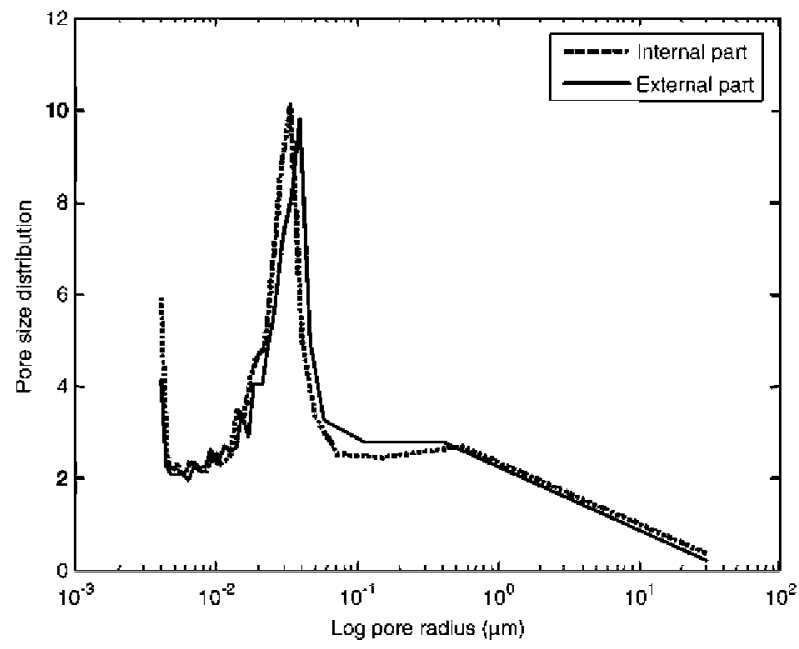

Fig. 10. Pore-size distribution for the CEM II/A-V 42.5R cement in the natural environment. 


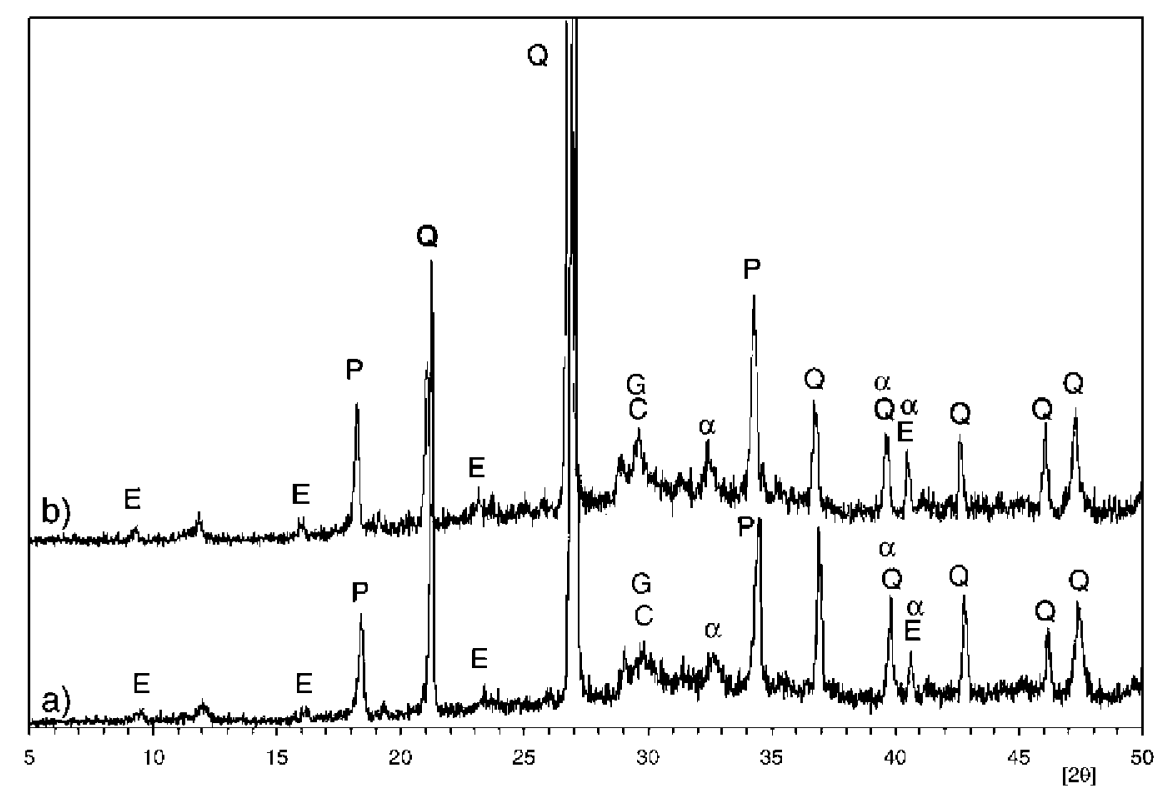

Fig. 11. X-ray diffraction patterns of CEM II/A-V in the anaerobic environment: a) internal part and b) external part: $\alpha \alpha^{\prime}-\mathrm{C}_{2} \mathrm{SiO}_{4} ; \mathrm{C} \mathrm{CaCO}_{3} ; \mathrm{P} \mathrm{Ca}(\mathrm{OH})_{2} ; \mathrm{Q} \mathrm{SiO}_{2}$; $\mathrm{E} \mathrm{Ca}_{6} \mathrm{Al}_{2}\left(\mathrm{SO}_{4}\right)(\mathrm{OH})_{12}$, G Gel C-S-H.

slurry for 24 months. The internal and external parts of the specimens were prepared. Fig. 11 shows the X-ray diffraction patterns for the internal part of the CEM II/A-V sample and the variation in the external part that was in contact with the slurry in anaerobic environment. Fig. 12 shows the X-ray diffraction patterns for the CEM IV/B (V) cements for the internal part and external part of the specimen in the anaerobic environment. Fig. 13 shows the X-ray diffraction patterns for CEM II/B-V in the same environment. The altered part has no new crystalline compounds. Nevertheless, an overall decrease of portlandite is observed in the external part of the samples. This decrease of portlandite is not due to external carbonation, because no calcium carbonate appeared.

\subsection{Discussion}

The general decrease in portlandite and porosity observed in the external part of the submerged samples together with the increase in compressive mechanical strength can be explained if the pozzolanic activity of the fly ash in the cements is taken into account. The pozzolanic activity of fly ash could have increased as a result of the high concentration of salts in the slurry and therefore its high ionic strength . This fact promotes an increase in phase solubility (portlandite and unreacted fly ash) favouring the reaction of the pozzolanic fly ash with the portlandite of the cement. Therefore the microstructure is denser, which decreases the porosity and pore size and increases

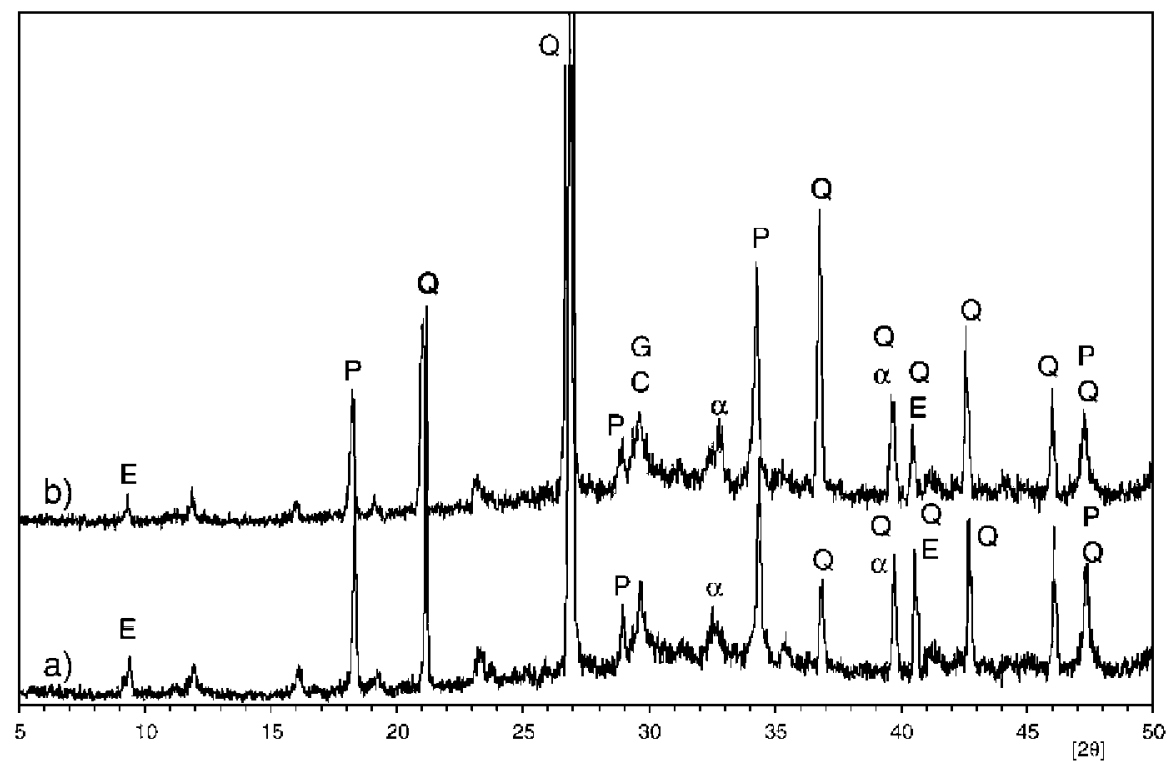

Fig. 12. X-ray diffraction patterns of CEM IV/B (V) in the anaerobic environment: a) internal part and b) external part: $\alpha \alpha^{\prime}-\mathrm{C}_{2} \mathrm{SiO}_{4} ; \mathrm{C} \mathrm{CaCO}_{3} ; \mathrm{P} \mathrm{Ca}(\mathrm{OH})_{2} ; \mathrm{Q} \mathrm{SiO}_{2}$ $\mathrm{E} \mathrm{Ca}_{6} \mathrm{Al}_{2}\left(\mathrm{SO}_{4}\right)(\mathrm{OH})_{12}$, G Gel C-S-H. 


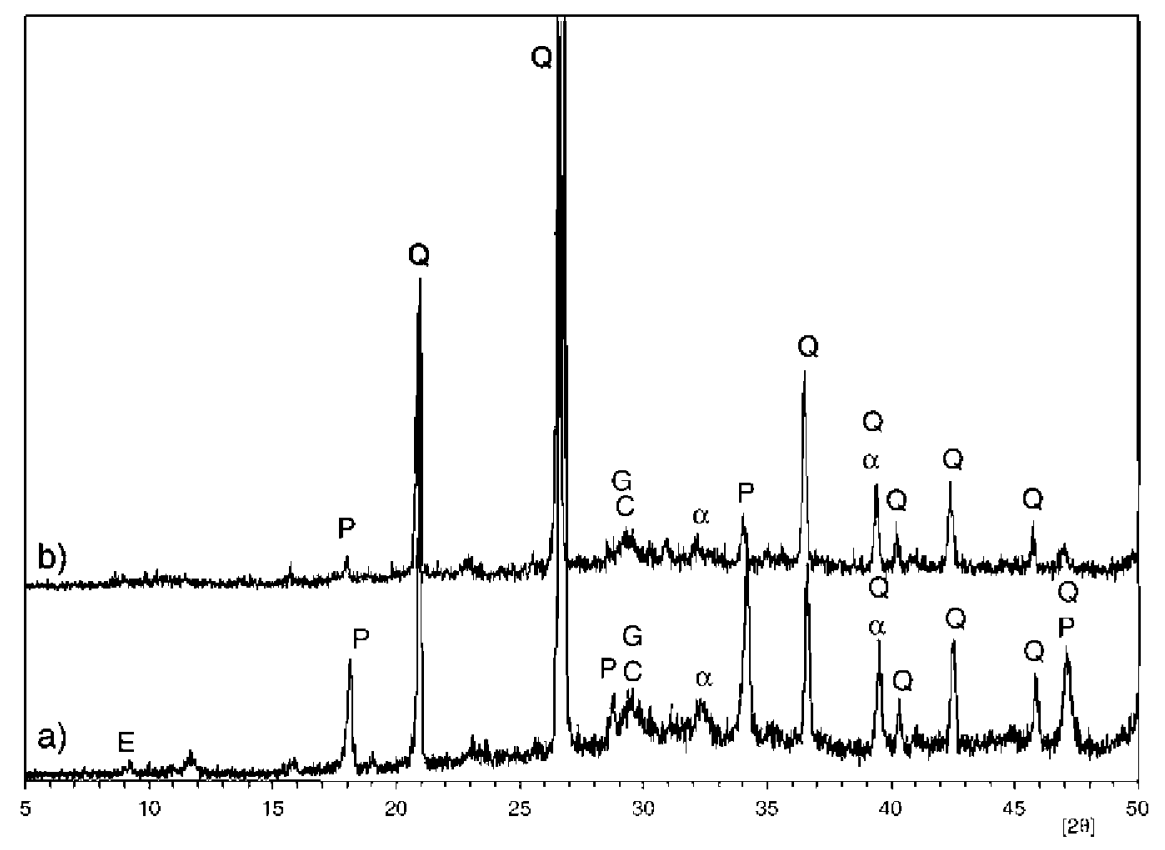

Fig. 13. X-ray diffraction patterns of CEM II/B-V in the anaerobic environment: a) internal part and b) external part: $\alpha \alpha^{\prime}-\mathrm{C}_{2} \mathrm{SiO}_{4} ; \mathrm{C} \mathrm{CaCO}_{3} ; \mathrm{P} \mathrm{Ca}(\mathrm{OH})_{2} ; \mathrm{Q} \mathrm{SiO} \mathrm{O}_{2}$; $\mathrm{E} \mathrm{Ca}_{6} \mathrm{Al}_{2}\left(\mathrm{SO}_{4}\right)(\mathrm{OH})_{12}$, G Gel C-S-H.

the compressive mechanical strength. This is compatible with the absence of calcium-compounds precipitated in the interphase of the samples with the slurry.

Another factor which can have an effect is the $\mathrm{pH}$ of the slurry (around $\mathrm{pH} 8$ ) in comparison with that of the mortar pore solution (around $\mathrm{pH}$ 12.7). This $\mathrm{pH}$ gradient can also provoke the dissolution of the basic portlandite, favouring the pozzolanic reaction.

This analysis makes it clear that in the external part of the cements studied, a relative increase in the ettringite (without CEM II/B) was noted. The increase in ettringite together with the pozzolanic activity of the fly ash could be the reason for the reduction in porosity seen in the external part of the samples of the cement types studied.

The lowest relative content of portlandite was found in the CEM II/B. This cement also showed the greatest initial porosity. This could be the reason for the more rapid penetration of the salts and the increase in the portlandite dissolution (Fig. 13).

\section{Conclusions}

- The flexural strength of all the mortar cements exposed to the outside environment showed an increase in strength in the first three months and a loss in resistance of 15 to $20 \%$ up to the 12 month point. The increase in flexural strength may be due to the increase in the level of hydration and the reduction due to the effects of micro-cracks caused by freeze-thaw cycles.

- The mechanical strength behaviour of mortar cements immersed in the slurry is the same in the aerobic and anaerobic environments. In these environments, there is a continual increase in strength throughout the duration of the test.
- This increase of mechanical strength could be due to the decrease of porosity and mainly pore size observed in the external part in contact with the slurry.

- The XRD results showed a decrease of portlandite content in the outside face in contact with the slurry.

- An increase of the pozzolanic activity of fly ash of cements is proposed to justify the general decrease of both portlandite and porosity observed in the external part of samples in contact with the slurry, together with the increase of compressive and flexural mechanical strength.

- The characteristics of the slurry (high concentration of salts and therefore high ionic strength), together with the $\mathrm{pH}$ (around 8) in comparison with that of mortar pore solution (around 12.7) promoted an increase of solubility of phases (portlandite and unreacted fly ash) favouring the pozzolanic fly ash reaction with the portlandite of cement. Therefore the microstructure is denser, decreasing the porosity and increasing the compressive mechanical strength. This is compatible with the absence of calcium - compounds precipitated in the external part of the samples in contact with the slurry.

- The slurry used cannot be considered as an aggressive agent for the mortar cements during the period of time studied, irrespective of the conditions being aerobic or anaerobic.

\section{Acknowledgements}

The authors gratefully acknowledge the financial support by the Minister of Science and Technology (Project No MAT200203945). Also they wish to express their thanks for the financial support given by the Spanish Institute of Cement and its Applications (IECA). Special appreciation to Javier Dorado for his dedication and help in this project. 


\section{References}

D.Q. Daudén, et al., Pig slurry application and irrigation effects on nitrate leaching in Mediterranean soil lysimeters, Journal of Environmental Quality 33 (6) (2004) 2290-2295.

S.J. Rodvang, et al., Changes in ground water quality in irrigated area of Southern Alberta, Journal of Environmental Quality 33 (2) (2004) 476-487.

E. González, et al., Weak points on cylindrical reinforced concrete irrigation tanks, IVth Int. Symposium Concrete for a Sustainable Agriculture, -Agro, -Aqua and Community Applications Proceeding, San Lorenzo de El Escorial, Madrid, 2005, pp. 335-346.

C.M. Ferrer, et al., Repair of a reinforced concrete tank for irrigation, IVth Int. Symposium Concrete for a Sustainable Agriculture, -Agro, -Aqua and Community Applications Proceeding, San Lorenzo de El Escorial, Madrid, 2005, pp. 291-298.

J. Calleja, The aggressive agents for concrete in agricultural livestock and agro-alimentary industries, IVth Int. Symposium Concrete for a Sustainable Agriculture, -Agro, -Aqua and Community Applications Proceeding, San Lorenzo de El Escorial, Madrid, 2005, pp. 139-152.

MOPU, Instrucción de Hormigón Estructural. EHE, Ministerio de Fomento, Madrid, Spain (1999).

N. De Belie, et al., Durability of building materials and components in the agricultural environment part III, concrete structures, Journal of Agricultural Engineering Research 76 (2000) 3-16.
A. Bertron, et al., Cement pastes alteration by liquid manure organic acids: chemical and mineralogical characterization, Cement and Concrete Research 35 (2005) 155-166.

A. Bertron, et al., Accelerated test of hardened cement pastes alteration by organic acids: analysis of the $\mathrm{pH}$ effect, Cement and Concrete Research 34 (2004) 1823-1835.

P. Huang, et al., Influence of HCL corrosion on the mechanical properties of concrete, Cement and Concrete Research 35 (2005) 584-589.

M. Cyr, et al., Efficiency of mineral admixtures in mortars: quantification of the physical and chemicals effects of fine admixtures in relation with compressive strength, Cement and Concrete Research 36 (2006) 264-277. Li Yong-Xin, et al., A study on the relationship between porosity of the cement paste with mineral additives and compressive strength of mortar based on this paste, Cement and Concrete Research 36 (2006) 1740-1743

A. Guerrero, et al., The role of the fly ash pozzolanic activity in simulated sulphate radioactive liquid waste, Waste Management 20 (2000) 51-58.

A. Moragues, et al., Equilibria of the chemical composition of the pore concrete solution. Part 1 calculation of the equilibria constant of synthetic solution, Cement and Concrete Research 17 (1988) 173-189.

A. Moragues, et al., Chemical equilibrium constants of the aqueous cement paste. Comparative study of synthetics and extracted solution, Materials Engineering 1 (2) (1991) 453-458.

A. Bertron, et al., Attack of cement pastes exposed to organic acids in manure, Cement and Concrete Composites 27 (2005) 898-909. 